\title{
TEP versus TAPP: comparison of the perioperative outcome in 17,587 patients with a primary unilateral inguinal hernia
}

\author{
F. Köckerling ${ }^{1} \cdot$ R. Bittner ${ }^{2} \cdot$ D. A. Jacob ${ }^{1} \cdot$ L. Seidelmann ${ }^{1} \cdot$ T. Keller ${ }^{3}$. \\ D. Adolf ${ }^{3}$ B. Kraft ${ }^{4}$ A. Kuthe
}

Received: 6 October 2014/ Accepted: 19 February 2015/Published online: 25 March 2015

(c) The Author(s) 2015. This article is published with open access at Springerlink.com

\begin{abstract}
Introduction More than 20 years since the introduction of TAPP and TEP into clinical routine, there is a lack of clarity due to conflicting comparative data. Therefore, more results from registries are needed.

Patients and methods A total of 17,587 patients were enrolled prospectively between September 1, 2009, and April 15, 2013, in the Herniamed registry. Of these patients, 10,887 (61.9\%) had a TAPP and $6700(38.1 \%)$ a TEP repair. The dependent variables were intra- and postoperative complication rates, number of reoperations as well as absolute and relative frequencies. The results of unadjusted analyses were verified via multivariable analyses.

Results Multivariable analysis verified the results of unadjusted analysis, indicating that the surgical technique did not have any significant impact, also while taking
\end{abstract}

F. Köckerling

ferdinand.koeckerling@vivantes.de

1 Department of Surgery and Center for Minimally Invasive Surgery, Academic Teaching Hospital of Charité Medical School, Vivantes Hospital, Neue Bergstraße 6, 13585 Berlin, Germany

2 Hernia Center, Winghofer Medicum, Winghofer Straße 42, 72108 Rottenburg am Neckar, Germany

3 StatConsult GmbH, Halberstädter Straße 40 a, 39112 Magdeburg, Germany

4 Department of General and Visceral Surgery, Diakonie Hospital, Rosenbergstraße 38, 70176 Stuttgart, Germany

5 Department of General and Visceral Surgery, German Red Cross Hospital, Lützerodestraße 1, 30161 Hannover, Germany account of other factors, on occurrence of intraoperative $[p=0.1648 ; \quad$ OR $=1.214(0.923 ; 1.596)]$ and general postoperative complications $[p=0.0738 ; \quad \mathrm{OR}=1.315$ $(0.974 ; 1.775)]$. Postoperative surgical complications $[\mathrm{OR}=2.323(1.882 ; 2.866) ; p<0.0001]$ were noted more often after TAPP. Furthermore, the hernia defect size [ $p<0.0001$; I vs III: OR $=0.439(0.313 ; 0.615)$, II vs III: $\mathrm{OR}=0.712 \quad(0.582 ; 0.872)]$ or scrotal $[p<0.0001$; $\mathrm{OR}=2.170(1.501 ; 3.137)]$ hernia and age $[p=0.0002$; 10 -year OR $=1.135(1.062 ; 1.213)]$ had a significant impact on the occurrence of postoperative complications. Complications were observed more commonly for larger hernia defects and a scrotal hernia. However, the difference in the postoperative complication rate between TEP and TAPP did not result in any difference in the reoperation rate (TEP $0.82 \%$ vs TAPP $0.90 \% ; p=0.6165$ ).

Conclusion The intraoperative and general postoperative complication rates as well as the reoperation rate for complications show no significant difference between TEP and TAPP. The higher postoperative complication rate for TAPP, which could be managed conservatively, is partly explained by larger defect sizes, more scrotal hernias and older age.

Keywords TEP - TAPP - Intraoperative complications · Postoperative complications - Inguinal hernia repair . Seroma

Already 20 years ago, the first study was published comparing the two minimally invasive surgical techniquestransabdominal preperitoneal patch plasty (TAPP) versus total extraperitoneal patch plasty (TEP) - for surgical repair of inguinal hernia [1]. Since then, 23 further studies [2-24] have been published, including four systematic 
reviews and meta-analyses [2-5], 10 randomized controlled [6-15], two population-based [16, 17] and six casecontrol and observational studies [18-24]. The findings are contradictory. Due to the confusing data situation, all four systematic reviews/meta-analyses concluded that operation-related results for TEP and TAPP were similar, and the superiority of one method over the other could not be demonstrated and further studies were needed. The reason for this lack of clarity, which has now persisted for more than 20 years since the introduction of both techniques into clinical routine practices, is due in particular to the limited quality of the studies conducted so far. For example, only in two $[11,15]$ of the randomized controlled trials (RCTs) was comparison of TAPP with TEP the primary endpoint. In the eight remaining studies, the main focus was on comparison of laparoscopic with open surgery. Another critical aspect was the small number of patients per group, which did not exceed 30 in the six RCTs [6-9, 11, 12]. Besides, a duration of operation of more than $100 \mathrm{~min}$ [14] as well as a $25 \%$ recurrence rate [6] suggests that the surgeons had not yet mastered the learning curve. Lack of experience must be viewed as being one of the main confounders as regards the results obtained. The study that must be deemed to be the best so far is the Swiss Registry Study published in 2012 [16]. Based on prospective data on 4552 patients undergoing TEP $(n=3457)$ and TAPP $(n=1095)$ of the Swiss Association of Laparoscopic and Thoracoscopic, both techniques were found to have a low complication rate, with that of TAPP being the lower of the two. Likewise, the duration of operation was shorter, but the length of hospital stay was half a day longer than for TEP. The reasons for these differences were not discussed. TAPP and TEP differ only in terms of the access route, and the inguinal surgical method is similar. If differences are found between the two techniques, these are due either to the use of a different access route, other hernia disease, or to variation of experience among surgeons.

On the basis of prospective data from the German hernia registry Herniamed collected for a very large patient group data in everyday routine practice, we now explore whether differences can also be discerned in the perioperative outcome between TEP and TAPP and what the likely reasons for these are.

\section{Patients and methods}

The Herniamed quality assurance study is a multicenter, internet-based hernia registry [25] into which 358 participating hospitals and surgeons engaged in private practice (Herniamed Study Group) in Germany, Austria and Switzerland (status: April 2013) had entered data prospectively on their patients who had undergone hernia surgery. All postoperative complications occurring up to 30 days after surgery are recorded. On 1-year follow-up, postoperative complications are once again reviewed when the general practitioner and patient complete a questionnaire. This present analysis compares the prospective data collected for all patients who had undergone primary unilateral inguinal hernia repair using either transabdominal preperitoneal patch plasty (TAPP) or total extraperitoneal patch plasty (TEP). Inclusion criteria were minimum age of 16 years and primary unilateral inguinal hernia. There were no exclusion criteria used in this study beyond those who fell out of the inclusion criteria. In total, 17,587 patients were enrolled between September 1, 2009, and April 15, 2013. Of these patients, 10,887 (61.9\%) had a TAPP repair and $6700(38.1 \%)$ a TEP repair.

The demographic and surgery-related parameters included age (years), sex (m/f), ASA classification (I-IV) as well as the proportion of scrotal inguinal hernias and the hernia defect size based on EHS classification (Hernia type: medial, lateral, femoral, scrotal. Defect size: Grade $\mathrm{I}=<1.5 \mathrm{~cm}$, Grade II $1.5-3 \mathrm{~cm}$, Grade III $>3 \mathrm{~cm}$ ) $[26$, 27]. The dependent variables were intra- and postoperative complication rates, number of reoperations as well as absolute and relative frequencies; continuous variables are displayed as mean, median, standard deviation and ranges.

All analyses were performed with the software SAS 9.2 (SAS Institute Inc. Cary, NY, USA) and deliberately reviewed to the full level of significance. Each $p$ value $\leq 0.05$ thus represents a statistically significant result. To discern differences between the groups in unadjusted analyses, Fisher's exact test was used for categorical outcome variables, and the $t$ test for continuous variables. For data that did not follow the normal distribution, as in the case of duration of operation and length of stay, the distribution was first transformed with the natural logarithm.

To rule out any confounding of data caused by different patient characteristics, the results of unadjusted analyses were verified via multivariable analyses in which, in addition to operation technique, other influence parameters were simultaneously reviewed.

To access influence factors in multivariable analyses, the general linear model was used for continuous outcome variables, and the binary logistic regression model for dichotomous outcome variables. Estimates for odds ratio (OR) or least square (LS) means, respectively, and the corresponding $95 \%$ confidence interval were given. For age [years], the 10-year OR estimate was given. Results are presented in tabular form, sorted by descending impact. Patients (and not hernia) were the level of analysis. 


\section{Results}

\section{Unadjusted analysis}

The patients in the TEP and TAPP groups did not differ in terms of age or gender distribution. However, there were significant differences between the two patient groups in respect of a number of other patient characteristics. Table 1 shows the overall demographic data. No difference was found with regard to age or gender distribution. However, more patients with a lower ASA status and larger hernia defects underwent the TAPP method. The TAPP technique was also used more often for hernias with 'medial,' 'scrotal' and 'combined' localization, while the TEP technique was employed more commonly for lateral hernias.

As regards the outcome variables, the two surgical methods differed in terms of duration of operation $(<0.0001)$ and of postoperative length of hospital stay $(<0.0001)$. Both were significantly longer for patients in the TAPP group. The mean duration of operation for the TAPP technique was $52.62 \pm 23.58 \mathrm{~min}$, and the median was $47 \mathrm{~min}$ (range 20-274 min). The mean duration of operation for the TEP technique at $48.58 \pm 21.52 \mathrm{~min}$ and median at $45 \mathrm{~min}$ (range $20-275 \mathrm{~min}$ ) was significantly lower (Table 2).

Table 1 Demographic and surgery-related parameters

\begin{tabular}{|c|c|c|c|}
\hline & TEP & TAPP & $p$ \\
\hline \multicolumn{4}{|c|}{ Demographic parameters } \\
\hline \multicolumn{4}{|l|}{ Age } \\
\hline Years $\pm \mathrm{SD}$ & $55.04 \pm 15.95$ & $55.40 \pm 15.71$ & 0.1441 \\
\hline Range & $16-100$ & $16-98$ & \\
\hline \multicolumn{4}{|l|}{ Sex } \\
\hline Male & $5862(87.49 \%)$ & $9441(86.72 \%)$ & \\
\hline Female & $838(12.51 \%)$ & $1446(13.28 \%)$ & 0.1394 \\
\hline \multicolumn{4}{|l|}{ ASA score } \\
\hline I & $2206(32.93 \%)$ & $3831(35.19 \%)$ & \\
\hline II & $3624(54.09 \%)$ & $5725(52.59 \%)$ & \\
\hline III & $851(12.7 \%)$ & $1313(12.06 \%)$ & \\
\hline IV & $19(0.28 \%)$ & $18(0.17 \%)$ & 0.0071 \\
\hline \multicolumn{4}{|c|}{ Surgery-related parameters } \\
\hline \multicolumn{4}{|l|}{ Hernia type } \\
\hline Medial & $2057(30.7 \%)$ & $4188(38.47 \%)$ & $<0.0001$ \\
\hline Lateral & $5274(78.72 \%)$ & $7364(67.64)$ & $<0.0001$ \\
\hline Femoral & $256(3.82 \%)$ & $479(4.4 \%)$ & 0.0627 \\
\hline Scrotal & $132(1.97 \%)$ & $325(2.99 \%)$ & $<0.0001$ \\
\hline \multicolumn{4}{|l|}{ Defect size } \\
\hline $\mathrm{I}(<1.5 \mathrm{~cm})$ & $1336(19.94 \%)$ & $1852(17.01 \%)$ & \\
\hline II $(1.5-3 \mathrm{~cm})$ & $4094(61.1 \%)$ & $6901(63.39 \%)$ & \\
\hline III $(>3 \mathrm{~cm})$ & $1270(18.96 \%)$ & $2134(19.6 \%)$ & $<0.0001$ \\
\hline
\end{tabular}

The mean length of hospital stay for the TAPP group patients was $1.93 \pm 2.22$ days, and for the TEP group patients, it was $1.88 \pm 2.19$ days (median in each case 2.0 days, range 1-63 days after TEP, 1-64 days after TAPP). Table 2 shows the total data for duration of operation and length of hospital stay.

Unadjusted analysis, at $1.19 \%$ for TEP and $1.40 \%$ for TAPP, did not reveal any significant differences in the intraoperative complications associated with the two surgical techniques $(p=0.2763)$.

Significantly, more complications were noted within the first 30 postsurgical days in the TAPP group (3.97\%; $p<0.0001)$. These were mainly due to the significant difference in the postoperative seroma rate (TEP $0.51 \%$ vs TAPP $3.06 \% ; p<0.001)$. Secondary bleeding occurred more frequently after TEP operation $(1.15 \% ; p=0.030)$, while seroma was seen more commonly after TAPP operation $(3.06 \%)$.

However, the difference in the postoperative complication rate between TEP and TAPP did not result in any difference in the reoperation rate due to surgical complications (TEP $0.82 \%$ vs TAPP $0.90 \% ; p=0.6165$ ), i.e., the difference in the postoperative complication rate between TEP and TAPP referred only to postoperative complications that were amenable to conservative treatment. Early recurrences were not a reason for reoperation (Table 3).

Viewed in global terms, no significant differences were noted between the two groups as regards general complications. In terms of individual general complications, a significant difference was seen for fever $(p=0.0228)$ and coronary heart disease $(p<0.0001)$. Both occurred more commonly in patients operated on with the TAPP technique ( 0.11 vs $0.2 \%$, respectively). Table 3 illustrates all data related to complications.

Data to compare recurrence rates can be provided only later at the end of 1-year follow-up.

\section{Multivariable analysis}

Multivariable analysis verified the results of unadjusted analysis, indicating that the surgical technique did not have

Table 2 Duration of operation. Length of stay and unadjusted $p$ values

\begin{tabular}{lcccccc}
\hline \multicolumn{1}{c}{ Mean } & SD & Min & Max & Median & $p$ \\
\hline \multicolumn{2}{l}{$\begin{array}{l}\text { Duration of operation (min) } \\
\text { TEP }\end{array} 48.53$} & 21.52 & 20 & 275 & 45 & $<0.0001$ \\
TAPP & 52.62 & 23.58 & 20 & 274 & 47 & \\
Length of stay (days) & & & & \\
TEP & 1.88 & 2.19 & 1 & 63 & 2 & $<0.0001$ \\
TAPP & 1.93 & 2.22 & 1 & 64 & 2 & \\
\hline
\end{tabular}


Table 3 Intra- and postoperative complications and unadjusted $p$ values

\begin{tabular}{llll}
\hline Unadjusted analysis & TEP & TAPP & $p$ \\
\hline Intraoperative complications & $80(1.19 \%)$ & $152(1.40)$ & 0.2763 \\
Bleeding & $53(0.79 \%)$ & $108(0.99 \%)$ & 0.1922 \\
Injuries (total) & $42(0.63 \%)$ & $77(0.71 \%)$ & 0.5705 \\
Vascular & $16(0.24 \%)$ & $34(0.31 \%)$ & 0.4662 \\
Bladder & $3(0.04 \%)$ & $15(0.14 \%)$ & 0.0867 \\
Bowel & $4(0.06 \%)$ & $14(0.13 \%)$ & 0.2256 \\
Nerve & $1(0.01 \%)$ & $0(0)$ & 0.381 \\
Postoperative complications & $114(1.70 \%)$ & $432(3.97 \%)$ & $<0.0001$ \\
Bleeding & $77(1.15 \%)$ & $89(0.82 \%)$ & 0.03 \\
Intestinal lesion & $0(0)$ & $4(0.04 \%)$ & 0.3048 \\
Impaired wound healing & $9(0.13 \%)$ & $10(0.09 \%)$ & 0.4798 \\
Seroma & $34(0.51 \%)$ & $333(3.06 \%)$ & $<0.0001$ \\
Infection & $3(0.04 \%)$ & $4(0.04 \%)$ & 1 \\
Intestinal obstruction & $0(0)$ & $6(0.06 \%)$ & 0.0891 \\
Reoperation & $55(0.82 \%)$ & $98(0.90 \%)$ & 0.6165 \\
General complications & $65(0.97 \%)$ & $137(1.26 \%)$ & 0.0935 \\
Fever & $1(0.01 \%)$ & $12(0.11 \%)$ & 0.0228 \\
Diarrhea & $0(0)$ & $4(0.04 \%)$ & 0.3048 \\
Coronary heart disease & $0(0)$ & $22(0.20 \%)$ & $<0.0001$ \\
Exitus letalis & $0(0)$ & $5(0.05 \%)$ & 0.1641 \\
\hline
\end{tabular}

any significant impact, also while taking account of other factors, on occurrence of intraoperative $[p=0.1648$; $\mathrm{OR}=1.214(0.923 ; 1.596)]$ and general complications $[p=0.0738$; OR $=1.315(0.974 ; 1.775)]$. The only variable impacting onset of intraoperative complications was medial inguinal hernia $(p=0.001)$. It had a preventive effect $[\mathrm{OR}=0.607(0.451 ; 0.816)]$ (Table 4$)$. Onset of general complications was affected by a number of parameters, but not the surgical technique. A lower ASA score $[p<0.001$, e.g., ASA III vs I: OR = 2.599 (1.645; $4.107)$, younger age $(10$-year $\mathrm{OR}=1.249$ [1.116; 1.398], $p=0.0001)$ as well as medial $[p=0.03$, OR $=0.577$ $(0.353 ; 0.942)]$ or lateral $[p=0.04 ;$ OR $=0.586(0.352$;
0.976)] inguinal hernia were preventive (Table 5), whereas a higher ASA score, older age and a scrotal hernia led to significantly more general postoperative complications.

The significant influence exerted by the surgical technique on the postoperative complication rate also persisted after adjustment of the other influence variables. Postoperative complications $[\mathrm{OR}=2.323 \quad(1.882 ; 2.866)$; $p<0.0001]$ were noted more often after TAPP. For a postoperative complication rate of $3.1 \%$, this would amount to around 43 out of every 1000 patients operated on with TAPP and to 19 out of every 1000 patients operated on with the TEP technique. Furthermore, the hernia defect size $[p<0.0001$; I vs III: OR $=0.439(0.313 ; 0.615)$, II vs
Table 4 Multivariable analysis of intraoperative complications

\begin{tabular}{llll}
\hline Parameter & Category & \multicolumn{2}{l}{ Intraoperative complications } \\
\cline { 3 - 4 } & & OR $[95 \% \mathrm{CI}]$ & $p$ \\
\hline EHS medial & Yes versus no & $0.607[0.451 ; 0.816]$ & 0.0001 \\
OP method & TAPP versus TEP & $1.214[0.923 ; 1.596]$ & 0.1648 \\
Age* & & $1.061[0.962 ; 1.170]$ & 0.2339 \\
Defect size & I $(<1.5 \mathrm{~cm})$ versus III $(>3 \mathrm{~cm})$ & $0.950[0.614 ; 1.470]$ & 0.5775 \\
& II $(1.5-3 \mathrm{~cm})$ versus III $(>3 \mathrm{~cm})$ & $0.851[0.614 ; 1.180]$ & \\
Sex & Male versus female & $1.248[0.819 ; 1.901]$ & 0.3032 \\
ASA & II versus I & $1.059[0.770 ; 1.455]$ & 0.9110 \\
& III versus I & $1.189[0.746 ; 1.897]$ & \\
& IV versus I & & \\
\hline
\end{tabular}

* 10-year estimate 
Table 5 Multivariable analysis of postoperative general complications

\begin{tabular}{llcc}
\hline Parameter & Category & \multicolumn{2}{l}{ Postoperative general complications } \\
\cline { 3 - 4 } & & OR $[95 \% \mathrm{CI}]$ & $p$ \\
\hline ASA & II versus I & $1.028[0.699 ; 1.511]$ & $<0.0001$ \\
& III versus I & $2.599[1.645 ; 4.107]$ & \\
& IV versus I & $4.329[0.970 ; 19.322]$ & 0.0001 \\
Age* & & $1.249[1.116 ; 1.398]$ & 0.0279 \\
EHS medial & Yes versus no & $0.577[0.353 ; 0.942]$ & 0.0401 \\
EHS lateral & Yes versus no & $0.586[0.352 ; 0.976]$ & 0.0738 \\
OP method & TAPP versus TEP & $1.315[0.974 ; 1.775]$ & 0.6148 \\
Defect size & I $(<1.5$ cm) versus III $(>3 \mathrm{~cm})$ & $1.232[0.761 ; 1.996]$ & \\
& II $(1.5-3$ cm) versus III $(>3 \mathrm{~cm})$ & $1.016[0.713 ; 1.447]$ & 0.4225 \\
EHS femoral & Yes versus no & $0.723[0.327 ; 1.598]$ & 0.6532 \\
Sex & Male versus female & $1.108[0.709 ; 1.731]$ & 0.0001 \\
EHS scrotal & Yes versus no & $0.912[0.411 ; 2.027]$ & \\
\hline
\end{tabular}

* 10-year estimate
III: $\mathrm{OR}=0.712(0.582 ; 0.872)]$, presence of medial $[p=0.0007, \quad$ OR $=0.610 \quad(0.458 ; \quad 0.811)], \quad$ lateral $[p=0.0043 ; \quad$ OR $=0.655 \quad(0.490 ; 0.876)]$ or scrotal $[p<0.0001 ;$ OR $=2.170(1.501 ; 3.137)]$ hernia and age $[p=0.0002 ; 10$-year OR $=1.135(1.062 ; 1.213)]$ had a significant impact on the occurrence of postoperative complications. Complications were observed more commonly for larger hernia defects and a scrotal hernia. Conversely, there were fewer postoperative complications in young patients and in patients with a medial or lateral hernia (Table 6).

Likewise, the multivariable model revealed the significant influence of the surgical technique on seroma formation or on secondary bleeding. For TAPP, postoperative seromas were seen significantly more often $[\mathrm{OR}=5.873 ;(4.116 ; 8.380), p<0.0001]$. For every 1000 patients undergoing surgery, there would therefore be 35 seromas for TAPP patients compared with six seromas on using TEP. The presence of a scrotal inguinal hernia also had a significant effect on the seroma rate, with this being conducive to onset of seroma $[p<0.0001$; OR $=2.784$ (1.837; 4.217)]; smaller hernia defects $[p=0.0002$; I vs III: $\mathrm{OR}=0.398(0.258 ; 0.615)$, II vs III: $\mathrm{OR}=0.754$ $(0.590 ; 0.964)]$, a lateral $[p=0.001 ;$ OR $=0.566(0.401$; $0.799)]$ or medial inguinal hernia $[p=0.012$; OR $=0.639$ $(0.451 ; 0.904)]$ each had a preventive effect, whereas older age $[p=0.003 ; 10$-year OR $=1.131(1.044 ; 1.226)]$ was conducive to onset of seroma.

For TAPP, secondary bleeding was less common $[\mathrm{OR}=0.734(0.539 ; 1.000), p=0.05]$. For a total secondary bleeding rate of $0.94 \%$, that complication would thus occur in eight out of every 1000 TAPP patients and in
Table 6 Multivariable analysis of postoperative surgical complications

\begin{tabular}{lllc}
\hline Parameter & Category & \multicolumn{2}{l}{ Postoperative surgical complications } \\
\cline { 3 - 4 } & & OR $[95 \% \mathrm{CI}]$ & $p$ \\
\hline OP method & TAPP versus TEP & $2.323[1.882 ; 2.866]$ & $<0.0001$ \\
Defect size & I $(<1.5 \mathrm{~cm})$ versus III $(>3 \mathrm{~cm})$ & $0.439[0.313 ; 0.615]$ & $<0.0001$ \\
& II $(1.5-3 \mathrm{~cm})$ versus III $(>3 \mathrm{~cm})$ & $0.712[0.582 ; 0.872]$ & \\
EHS scrotal & Yes versus no & $2.170[1.501 ; 3.137]$ & $<0.0001$ \\
Age* & & $1.135[1.062 ; 1.213]$ & 0.0002 \\
EHS medial & Yes versus no & $0.610[0.458 ; 0.811]$ & 0.0007 \\
EHS lateral & Yes versus no & $0.655[0.490 ; 0.876]$ & 0.0043 \\
ASA & II versus I & $1.097[0.883 ; 1.363]$ & 0.2321 \\
& III versus I & $1.135[0.834 ; 1.545]$ & \\
Sex & IV versus I & $3.075[1.023 ; 9.247]$ & \\
EHS femoral & Male versus female & $1.120[0.832 ; 1.509]$ & 0.4547 \\
& Yes versus no & $1.116[0.700 ; 1.779]$ & 0.6449 \\
\hline
\end{tabular}

* 10-year estimate 
11 out of every 1000 TEP patients. Conversely, the secondary bleeding rate was influenced more by the ASA status $(p=0.005)$, medial inguinal hernia $(p=0.02)$ and age $(p=0.04)$. A low ASA score, e.g., ASA III versus I: $\mathrm{OR}=1.760[1.038 ; 2.982]$, medial hernia $[\mathrm{OR}=0.540$ $(0.323 ; 0.901)]$ and young age $[10$-year $\mathrm{OR}=1.135$ (1.007; 1.279), $p=0.0387]$ had a preventive effect on onset of secondary bleeding.

Multivariable analysis also confirmed that the surgical technique did not have any impact on the reoperation rate linked to complications. However, it was demonstrated that a high ASA classification as well as large hernia defects had a significant impact on the complication-related reoperation rate (Table 7).

It was also possible to confirm the significant influence of the surgical technique on the duration of operation $(p<0.0001)$ and the postoperative length of hospital stay $(p<0.0001)$. The operation took longer for TAPP [49.74 $\mathrm{min}$ (47.76; 51.82), and was $45.86 \mathrm{~min}$ (44.00; 47.79) for TEP]. Other significant influence variables identified for the duration of operation were sex $(p<0.0001)$, ASA classification $(p=0.02)$, hernia defect size $(p<0.0001)$ and medial $(p<0.0001)$, femoral $(p=0.2)$ and scrotal $(p<0.0001)$ hernias. Die duration of operation was significantly longer for men, for patients with a lower ASA score, larger hernia defect or if surgery was performed for a femoral or scrotal hernia. Conversely, the duration of surgery was significantly shorter for a medial hernia.

In the multivariable model, too, the postoperative length of hospital stay was significantly longer for patients operated on with the TAPP technique $[2.19 \mathrm{~d}(2.08 ; 2.31)$ for TAPP and $2.27 \mathrm{~d}(2.16 ; 2.39)$ for TEP]. Besides, other variables whose significant influence was confirmed were sex $(p<0.0001)$, ASA classification $(p<0.0001)$, hernia defect size $(p=0.0002)$, medial $(p=0.006)$, scrotal $(p<0.0001)$ or femoral $(p=0.02)$ hernia and also age $(p<0.0001)$. The length of hospital stay was prolonged for cases with higher ASA score or the presence of a scrotal or femoral hernia. It was also longer for rising age. The length of stay was shorter for a medial inguinal hernia or a smaller hernia defect. It was also significantly shorter for men.

\section{Discussion}

This Registry study compared prospective data for 10,887 TAPP operations with 6700 TEP operations for primary unilateral inguinal hernia on the basis of the perioperative outcomes. These perioperative results were first investigated using unadjusted, and then multivariable, analysis for differences between TAPP and TEP, while identifying other influence variables. Thanks to the large number of cases, it was possible to identify the significant impact of even small differences, even if such an effect was not of clinical relevance.

The EHS classification for inguinal hernia has been used for the first time in the Herniamed Registry for precise stratification of the patient collective [25].

This makes it easier to identify variables impacting the perioperative outcome; it also makes it easier to identify patient characteristics as well as method-independent variables that affect the outcome.

For example, on the basis of the Herniamed data, no difference was seen in the age or gender distribution between the TEP and TAPP groups. Conversely, significant differences were discerned between the TEP and TAPP groups in terms of the proportion of medial, lateral and
Table 7 Multivariable analysis of reoperation

\begin{tabular}{llrl}
\hline Parameter & Category & Reoperation & \\
\cline { 3 - 4 } & & OR $[95 \% \mathrm{CI}]$ & 0.0153 \\
\hline ASA & II versus I & $1.074[0.709 ; 1.627]$ & \\
& III versus I & $1.845[1.075 ; 3.166]$ & \\
& IV versus I & $5.656[1.232 ; 25.955]$ & \\
Defect size & I $(<1.5 \mathrm{~cm})$ versus III $(>3 \mathrm{~cm})$ & $0.423[0.227 ; 0.787]$ & 0.0135 \\
& II $(1.5-3 \mathrm{~cm})$ versus III $(>3 \mathrm{~cm})$ & $0.658[0.454 ; 0.954]$ & \\
EHS scrotal & Yes versus no & $1.988[1.007 ; 3.922]$ & 0.0478 \\
EHS medial & Yes versus no & $0.720[0.436 ; 1.188]$ & 0.1986 \\
Age* & & $1.054[0.932 ; 1.192]$ & 0.3990 \\
OP method & TAPP versus TEP & $1.097[0.786 ; 1.533]$ & 0.5855 \\
EHS femoral & Yes versus no & $0.849[0.318 ; 2.262]$ & 0.7431 \\
EHS lateral & Yes versus no & $0.918[0.540 ; 1.560]$ & 0.7528 \\
Sex & Male versus female & $1.009[0.586 ; 1.735]$ & 0.9754 \\
\hline$*$ 10-year estimate & & &
\end{tabular}


scrotal hernias. That also applied for the defect size. Significantly, more medial and scrotal hernias as well as larger defects were seen for the TAPP group. Despite that disparity, no difference was seen in the intraoperative complication rate between TEP and TAPP. The significant difference in the postoperative complication rates, which were higher for TAPP (TEP 1.70 vs TAPP 3.97; $p<0.0001$ ), was due to a significantly higher seroma rate (TEP $0.51 \%$ vs TAPP $3.06 \%$; $p<0.0001$ ). In multivariable analysis, the variables identified as impacting onset of a postoperative complication, in particular seroma formation, were a large hernia defect and a scrotal hernia. Both hernia pathologies were found significantly more often in patients operated on with the TAPP technique, hence this higher complication rate compared with TEP was observed across different patient collectives. However, despite adjustment of these parameters, TAPP per se proved to be a lower but independent risk factor. To what extent the various surgeon's experience played a role here cannot be elucidated on the basis of that analysis. Since there is a greater number of TAPP surgeons in the Herniamed Registry, it is presumed that TEP tends to be performed more by specialists.

Nonetheless, the significant difference in the postoperative complication rates did not give rise to a significant difference in the complication-related reoperation rates between TEP and TAPP. Hence, the implicated complications were essentially postoperative complications that were amenable to conservative treatment in the TAPP group.

As such, the difference in perioperative outcome between TEP and TAPP must be imputed more to the indication than to the surgical technique. Since a greater number of large inguinal hernias and scrotal hernias were operated on with the TAPP than the TEP technique, a significantly higher rate of postoperative complications amenable to conservative treatment occurred in the former. These manifested as seromas, something that was consistent with these findings. Therefore, by adopting a tailored approach for inguinal hernia surgery, as recommended in the guidelines [26] on the basis of a decision-making tree [28], the indication for use of the laparoscopic technique for very large hernias and for scrotal hernias should be based on ultra stringent criteria. If the surgeon has only limited experience of the laparoscopic technique, it would be advisable to opt instead for the Lichtenstein technique in the case of a scrotal hernia with a hernia sac reaching as far as the scrotum. Only experienced TAPP experts should use laparoscopic repair for scrotal hernias. It appears that TEP surgeons are more reluctant to use this technique for scrotal hernia because of the challenging anatomic situation, indicating instead open surgical repair.
The differences in the patient collective between TEP and TAPP also explain the somewhat longer duration of operation and length of hospital stay for TAPP compared with TEP. Surgery for larger defects and a greater number of scrotal hernias result in a longer duration of operation. The significantly higher incidence of postoperative complications also leads to a longer mean length of hospital stay. However, these differences are minor and can be identified as significant only thanks to the large number of patients.

Secondary bleeding occurred significantly more often after TEP than after TAPP. In the case of TEP, the extraperitoneal space is markedly narrower than the abdominal space and impairs visibility when using current for TEP dissection. Hence, many TEP surgeons avoid the use of current and perform dissection without current, using instead a pulling and counterpulling technique, while tearing the connective tissue bridges between the anatomic structures. That inevitably results in a higher rate of secondary bleeding. Therefore, on the basis of the Herniamed data, the use current must also be recommended for dissection to reduce the secondary bleeding rate. While the use of current for dissection with the TEP technique is more onerous because of the need to clean the optics more frequently, and presumably also prolongs the duration of operation, it should be used preferably in the interest of patient risk minimization. But extreme care must be exercised when using current at the level of the peritoneum because this can cause adhesions to the intestines as well as thermal damage.

In summary, these data from the Herniamed Registry reveal that there are significant differences in perioperative outcome between TEP and TAPP. Thanks to the precise method employed for classification and for documentation of inguinal hernia defect sizes, significant differences can be identified between patients in the patient collective operated on with the TEP compared with the TAPP technique in terms of risk stratification. These differences attest to the fact that the patients operated on with the TAPP technique had significantly larger defect sizes and a significantly greater proportion of scrotal hernias. The significantly higher postoperative seroma rate in patients operated on with the TAPP technique, leading to a significantly higher overall postoperative complication rate, is therefore to be expected. To reduce the seroma rate for a directly accessible hernia, it is recommended to use widespread electrocoagulation of the pseudohernia sac for sloughing off even the smallest blood and lymph vessels or inversion of the pseudohernia sac with fixation to Cooper's ligament $[29,30]$.

Consequently, the indication for TAPP for large hernia defects and for scrotal hernias should be tailored to the surgeon's experience. Large hernias and scrotal hernias 
should be repaired either by a very experienced TAPP surgeon or, using a tailored approach, using the open Lichtenstein technique. Current should be employed for dissection in both TEP and TAPP operations, but extreme care must be taken to avoid secondary bleeding.

Finally, analysis of a large patient collective in routine practice has revealed that 25 years after the introduction of laparoscopic surgical techniques for inguinal hernia repair, TAPP and TEP techniques can be carried out with a very low rate of predominantly harmless complications and with an acceptable duration of operation. Today, onset of serious visceral and vascular complications is rare, even in non-specialist hospitals, but the situation is still not satisfactory. However, a further reduction can only be achieved through continuing training, accretion of knowledge and improvement of the surgical techniques.

Apart from that, assuming a comparable patient group, identical indication and adequately experienced surgeons, similar results can be achieved with the TEP and TAPP technique. That is borne out by the comparable reoperation rate for postoperative complications. The technical provisions set out in the international guidelines should continue to be observed for conduct of both TAPP and TEP [29, 30].

Acknowledgments Ferdinand Köckerling-Grants to fund the Herniamed Registry from Johnson\&Johnson, Norderstedt, Karl Storz, Tutlingen, PFM Medical, Cologne, Dahlhausen, Cologne, B Braun, Tutlingen, MenkeMed, Munich and BARD, Karlsruhe.

Disclosures R. Bittner, D. A. Jacob, L. Seidelmann, T. Keller, D. Adolf, B. Kraft and A. Kuthe have no conflicts of interest or financial ties to disclose.

Open Access This article is distributed under the terms of the Creative Commons Attribution License which permits any use, distribution, and reproduction in any medium, provided the original author(s) and the source are credited.

\section{Appendix: Herniamed Study Group}

\section{Scientific Board}

Köckerling, Ferdinand (Chairman); Berger, Dieter; Bittner, Reinhard; Fortelny, René; Koch, Andreas; Kraft, Barbara;Kuthe, Andreas; Lorenz, Ralph; Mayer, Franz; Moesta, Kurt Thomas; Niebuhr, Henning; Peiper, Christian; Pross, Matthias; Reinpold, Wolfgang; Simon, Thomas; Stechemesser, Bernd; Unger, Solveig.

\section{Participants}

Ahmetov, Azat (Saint-Petersburg); Alapatt, Terence Francis (Frankfurt/Main); Anders, Stefan (Berlin); Anderson, Jürina (Würzburg); Arndt, Anatoli (Elmshorn);
Asperger, Walter (Halle); Avram, Iulian (Saarbrücken); Barkus; Jörg (Velbert); Becker, Matthias (Freital); Behrend, Matthias (Deggendorf); Beuleke, Andrea (Burgwedel); Berger, Dieter (Baden-Baden); Bittner, Reinhard (Rottenburg); Blumberg, Claus (Lübeck); Böckmann, Ulrich (Papenburg); Böhle, Arnd Steffen (Bremen); Böttger, Thomas Carsten (Fürth); Borchert, Erika (Grevenbroich); Born, Henry (Leipzig); Brabender, Jan (Köln); Breitenbuch von, Philipp (Radebeul); Brüggemann, Armin (Kassel); Brütting, Alfred (Erlangen); Budzier, Eckhard (Meldorf); Burghardt, Jens (Rüdersdorf); Carus, Thomas (Bremen); Cejnar, Stephan-Alexander (München); Chirikov, Ruslan (Dorsten); Comman, Andreas (Bogen); Crescenti, Fabio (Verden/Aller); Dapunt, Emanuela (Bruneck); Decker, Georg (Berlin); Demmel, Michael (Arnsberg); Descloux, Alexandre (Baden); Deusch, Klaus-Peter (Wiesbaden); Dick, Marcus (Neumünster); Dieterich, Klaus (Ditzingen); Dietz, Harald (Landshut); Dittmann, Michael (Northeim); Dornbusch, Jan (Herzberg/Elster); Drummer, Bernhard (Forchheim); Eckermann, Oliver (Luckenwalde); Eckhoff, Jörn/Hamburg); Elger, Karlheinz (Germersheim); Engelhardt, Thomas (Erfurt); Erichsen, Axel (Friedrichshafen); Eucker, Dietmar (Bruderholz); Fackeldey, Volker (Kitzingen); Farke, Stefan (Delmenhorst); Faust, Hendrik (Emden); Federmann, Georg (Seehausen); Feichter, Albert (Wien); Fiedler, Michael (Eisenberg); Fischer, Ines (Wiener Neustadt); Fortelny, René H. (Wien); Franczak, Andreas (Wien); Franke, Claus (Düsseldorf); Frankenberg von, Moritz (Salem); Frehner, Wolfgang (Ottobeuren); Friedhoff, Klaus (Andernach); Friedrich, Jürgen (Essen); Frings, Wolfram (Bonn); Fritsche, Ralf (Darmstadt); Frommhold, Klaus (Coesfeld); Frunder, Albrecht (Tübingen); Fuhrer, Günther (Reutlingen); Gassler, Harald (Villach); Gerdes, Martin (Ostercappeln); Gilg, KaiUwe (Hartmannsdorf); Glaubitz, Martin (Neumünster); Glutig, Holger (Meißen); Gmeiner, Dietmar (Bad Dürnberg); Göring, Herbert (München); Grebe, Werner (Rheda-Wiedenbrück); Grothe, Dirk (Melle); Gürtler, Thomas (Zürich); Hache, Helmer (Löbau); Hämmerle, Alexander (Bad Pyrmont); Haffner, Eugen (Hamm); Hain, Hans-Jürgen (Groß-Umstadt); Hammans, Sebastian (Lingen); Hampe, Carsten (Garbsen); Harrer, Petra (Starnberg); Heinzmann, Bernd (Magdeburg); Heitland, Tim (München); Helbling, Christian (Rapperswil); Hempen, Hans-Günther (Cloppenburg); Henneking, Klaus-Wilhelm (Bayreuth); Hermes, Wolfgang (Weyhe); Herrgesell, Holger (Berlin); Herzing, Holger Höchstadt); Hessler, Christian (Bingen); Hildebrand, Christiaan (Langenfeld); Höferlin, Andreas (Mainz); Hoffmann, Michael (Kassel; Hofmann, Eva M. (Frankfurt/Main); Hopfer, Frank (Eggenfelden); Hornung, Frederic (Wolfratshausen); Hügel, Omar (Hannover); Hüttemann, Martin 
(Oberhausen); Huhn, Ulla (Berlin); Imdahl, Andreas (Heidenheim); Jacob, Dietmar (Bielefeld); Jenert, Burghard (Lichtenstein); Jugenheimer, Michael (Herrenberg); Junger, Marc (München); Käs, Stephan (Weiden); Kahraman, Orhan (Hamburg); Kaiser, Christian (Westerstede); Kaiser, Stefan (Kleinmachnow); Kapischke, Matthias (Hamburg); Karch, Matthias (Eichstätt); Keck, Heinrich (Wolfenbüttel); Keller, Hans W. (Bonn); Kienzle, Ulrich (Karlsruhe); Kipfmüller, Brigitte (Köthen); Kirsch, Ulrike (Oranienburg); Klammer, Frank (Ahlen); Klatt, Richard (Hagen); Kleemann, Nils (Perleberg); Klein, Karl-Hermann (Burbach); Kleist, Sven (Berlin); Klobusicky, Pavol (Bad Kissingen); Kneifel, Thomas (Datteln); Knoop, Michael (Frankfurt/Oder); Knotter, Bianca (Mannheim); Koch, Andreas (Cottbus); Köckerling, Ferdinand (Berlin); Köhler, Gernot (Linz); König, Oliver (Buchholz); Kornblum, Hans (Tübingen); Krämer, Dirk (Bad Zwischenahn); Kraft, Barbara (Stuttgart); Kreissl, Peter (Ebersberg); Krones, Carsten Johannes (Aachen); Kruse, Christinan (Aschaffenburg); Kube, Rainer (Cottbus); Kühlberg, Thomas (Berlin); Kuhn, Roger (Gifhorn); Kusch, Eduard (Gütersloh); Kuthe, Andreas (Hannover); Ladberg, Ralf (Bremen); Ladra, Jürgen (Düren); Lahr-Eigen, Rolf (Potsdam); Lainka, Martin (Wattenscheid); Lammers, Bernhard J. (Neuss); Lancee, Steffen (Alsfeld); Larusson, Hannes Jon (Pinneberg); Lauschke, Holger (Duisburg); Leher, Markus (Schärding); Leidl, Stefan (Waidhofen/Ybbs); Lenz, Stefan (Berlin); Lesch, Alexander (Kamp-Lintfort); Lienert, Mark (Duisburg); Limberger, Andreas (Schrobenhausen); Locher, Martin (Kiel); Loghmanieh, Siawasch (Viersen); Lorenz, Ralph (Berlin); Mallmann, Bernhard (Krefeld); Manger, Regina (Schwabmünchen); Maurer, Stephan (Münster); Mayer, Franz (Salzburg); Menzel, Ingo (Weimar); Meurer, Kirsten (Bochum); Meyer, Moritz (Ahaus); Mirow, Lutz (Kirchberg); Mittenzwey, Hans-Joachim (Berlin); Mörder-Köttgen, Anja (Freiburg); Moesta, Kurt Thomas (Hannover); Moldenhauer, Ingolf (Braunschweig); Morkramer, Rolf (Xanten); Mosa, Tawfik (Merseburg); Müller, Hannes (Schlanders); Münzberg, Gregor (Berlin); Mussack, Thomas (St. Gallen); Neumann, Jürgen (Haan); Niebuhr, Henning (Hamburg); Nölling, Anke (Burbach); Nostitz, Friedrich Zoltán (Mühlhausen); Obermaier, Straubing); Öz-Schmidt, Meryem (Hanau); Oldorf, Peter (Usingen); Olivieri, Manuel (Pforzheim); Pawelzik, Marek (Hamburg); Peiper, Christian (Hamm); Pertl, Alexander (Spittal/Drau); Philipp, Mark (Rostock); Pickart, Lutz (Bad Langensalza); Pizzera, Christian (Graz); Pöllath, Martin (Sulzbach-Rosenberg); Possin, Ulrich (Laatzen); Prenzel, Klaus (Bad Neuenahr-Ahrweiler); Pröve, Florian (Goslar); Pronnet, Thomas (Fürstenfeldbruck); Pross, Matthias (Berlin); Puff, Johannes (Dinkelsbühl); Rabl, Anton (Passau); Rapp, Martin
(Neunkirchen); Reck, Thomas (Püttlingen); Reinpold, Wolfgang (Hamburg); Reuter, Christoph (Quakenbrück); Richter, Jörg (Winnenden); Riemann, Kerstin (AlzenauWasserlos); Rodehorst, Anette (Otterndorf); Roehr, Thomas (Rödental); Roncossek, Bremerhaven); Roth Hartmut (Nürnberg); Sardoschau, Nihad (Saarbrücken); Sauer, Gottfried (Rüsselsheim); Sauer, Jörg (Arnsberg); Seekamp, Axel (Freiburg); Seelig, Matthias (Bad Soden); Seiler, Christoph Michael (Warendorf); Seltmann, Cornelia (Hachenburg); Senkal, Metin (Witten); Shamiyeh, Andreas (Linz); Shang, Edward (München); Siemssen, Björn (Berlin); Sievers, Dörte (Hamburg); Silbernik, Daniel (Bonn); Simon, Thomas (Sinsheim); Sinn, Daniel (Olpe); Sinning, Frank (Nürnberg); Smaxwil, Constatin Aurel (Stuttgart); Schabel, Volker (Kirchheim/Teck); Schadd, Peter (Euskirchen); Schassen von, Christian (Hamburg); Schattenhofer, Thomas (Vilshofen); Scheidbach, Hubert (Neustadt/Saale); Schelp, Lothar (Wuppertal); Scherf, Alexander (Pforzheim); Scheyer, Mathias (Bludenz); Schimmelpenning, Hendrik (Neustadt in Holstein); Schinkel, Svenja (Kempten); Schmid, Michael (Gera); Schmid, Thomas (Innsbruck); Schmidt, Rainer (Paderborn); Schmidt, Sven-Christian (Berlin); Schmidt, Ulf (Mechernich); Schmitz, Heiner (Jena); Schmitz, Ronald (Altenburg); Schöche, Jan (Borna); Schoenen, Detlef (Schwandorf); Schrittwieser, Rudolf/Bruck an der Mur); Schroll, Andreas (München); Schultz, Christian (Bremen-Lesum); Schultz, Harald (Landstuhl); Schulze, Frank P. Mülheim an der Ruhr); Schumacher, Franz-Josef (Oberhausen); Schwab, Robert (Koblenz); Schwandner, Thilo (Lich); Schwarz, Jochen Günter (Rottenburg); Schymatzek, Ulrich (Radevormwald); Spangenberger, Wolfgang (Bergisch-Gladbach); Sperling, Peter (Montabaur); Staade, Katja (Düsseldorf); Staib, Ludger (Esslingen); Stamm, Ingrid (Heppenheim); Stark, Wolfgang (Roth); Stechemesser, Bernd (Köln); Steinhilper, Uz (München); Stern, Oliver (Hamburg); Stolte, Thomas (Mannheim); Stopinski, Jürgen (Schwalmstadt); Stubbe, Hendrik (Güstrow/); Stülzebach, Carsten (Friedrichroda); Tepel, Jürgen (Osnabrück); Terzić, Alexander (Wildeshausen); Teske, Ulrich (Essen); Thews, Andreas (Schönebeck); Tillenburg, Wolfgang (Marktheidenfeld); Timmermann, Wolfgang (Hagen); Train, Stefan H. (Gronau); Trauzettel, Uwe (Plettenberg); Triechelt, Uwe (Langenhagen); Ulcar, Heimo (Schwarzach im Pongau); Unger, Solveig (Chemnitz); Verweel, Rainer (Hürth); Vogel, Ulrike (Berlin); Voigt, Rigo (Altenburg); Voit, Gerhard (Fürth); Volkers, Hans-Uwe (Norden); Vossough, Alexander (Neuss); Wallasch, Andreas (Menden); Wallner, Axel (Lüdinghausen); Warscher, Manfred (Lienz); Warwas, Markus (Bonn); Weber, Jörg (Köln); Weiß, Johannes (Schwetzingen); Weißenbach, Peter (Neunkirchen); Werner, Uwe (Lübbecke-Rahden); Wessel, 
Ina (Duisburg); Weyhe, Dirk (Oldenburg); Wieber, Isabell (Köln); Wiesmann, Aloys (Rheine); Wiesner, Ingo (Halle); Woehe, Fritz (Sanderhausen); Wolf, Claudio (Neuwied); Yildirim, Selcuk (Berlin); Zarras, Konstantinos (Düsseldorf); Zeller, Johannes (Waldshut-Tiengen); Zhorzel, Sven (Agatharied); Zuz, Gerhard (Leipzig);

\section{References}

1. Tetik C, Arregui ME, Dulucq JL, Fitzgibbons RJ, Franklin ME, McKernan JB, Rosin RD, Schultz LS, Toy FK (1994) Complications and recurrences associated with laparoscopic repair of groin hernias. A multi-institutional retrospective analysis. Surg Endosc 8(11):1316-1322

2. McCormack K, Wake BL, Fraser C, Vale L, Perez J, Grant A (2005) Transabdominal pre-peritoneal (TAPP) versus totally extraperitoneal (TEP) laparoscopic techniques for inguinal hernia repair: a systematic review. Hernia 9:109-114

3. ÓReilly EA, Burke JP, O‘Connell PR (2012) A meta-analysis of surgical morbidity and recurrence after laparoscopic and open repair of primary unilateral inguinal hernia. Ann Surg 255:846-853

4. Bracale U, Melillo P, Pignata G, Di Salvo E, Rovani M, Merola G, Pecchia L (2012) Which is the best laparoscopic approach for inguinal hernia repair: TEP or TAPP? a systematic review of the literature with a network meta-analysis. Surg Endosc 26:3355-3366

5. Antoniou SA, Antoniou GA, Bartsch DK, Fendrich V, Koch OO, Pointner R, Granderath FA (2013) Transabdominal preperitoneal versus totally extraperitoneal repair of inguinal hernia: a metaanalysis of randomized studies. Am J Surg 206:245-252

6. Schrenk P, Woisetschläger R, Rieger R, Wayand W (1996) Prospective randomized trial comparing postoperative pain and return to physical activity after transabdominal preperitoneal, total preperitoneal or Shouldice technique for inguinal hernia repair. Br J Surg 83:1563-1566

7. Heikkinen T, Bringman S, Ohtonen P, Kunelius P, Haukipuro K, Hulkko A (2004) Five-year outcome of laparoscopic and Lichtenstein hernioplasties. Surg Endosc 18(3):518-522

8. Dedemadi G, Sgourakis G, Karaliotas C, Christofides T, Kouraklis G, Karaliotas C (2006) Comparison of laparoscopic and open tension-free repair of recurrent inguinal hernias: a prospective randomized study. Surg Endosc 20:1099-1104

9. Butler RE, Burke R, Schneider JJ, Brar H, Lucha PA Jr (2007) The economic impact of laparoscopic inguinal hernia repair: results of a double-blinded, prospective, randomized trial. Surg Endosc 21:387-390

10. Pokorny H, Klingler A, Schmid T, Fortelny R, Hollinsky C, Kawji R, Steiner E, Pernthaler H, Függer R, Scheyer M (2008) Recurrence and complications after laparoscopic versus open inguinal hernia repair: results of a prospective randomized multicenter trial. Hernia 12:385-389

11. Zhu Q, Mao Z, Yu B, Jin J, Zheng M, Li J (2009) Effects of persistent $\mathrm{CO}(2)$ insufflation during different laparoacopic inguinal hernioplasty: a prospective, randomized, controlled study. J Laparoendosc Adv Surg Tech A 19(5):611-614

12. Hamza Y, Gabr E, Hammadi H, Khalil R (2010) Four-arm randomized trial comparing laparoscopic and open hernia repairs. Int J Surg 8:25-28

13. Gong K, Zhang N, Lu Y, Zhu B, Zhang Z, Du D, Zhao X, Jiang H (2011) Comparison of the open tension-free mesh-plug, transabdominal preperitoneal (TAPP), and totally extraperitoneal
(TEP) laparoscopic techniques for primary unilateral inguinal hernia repair: a prospective randomized controlled trial. Surg Endosc 25:234-239

14. Günal O, Ozer S, Gürleyik E, Bahebasi T (2007) Does he approach to the groin make a difference in hernia repair? Hernia 11:429-434

15. Krishna A, Misra MC, Bansal VK, Kumar S, Rajeshwari S, Chabra A (2012) Laparoscopic inguinal hernia repair: transabdominal preperitoneal (TAPP) versus totally extraperitoneal (TEP) approach: a prospective randomized controlled trial. Surg Endosc 26:639-649

16. Gass M, Banz VM, Rosella L, Adamina M, Candinas D, Güller U (2012) TAPP or TEP? population-based analysis of prospective data on 4,552 patients undergoing endoscopic inguinal hernia repair. World J Surg 36:2782-2786

17. Wittenbecher F, Scheller-Kreinsen D, Röttger J, Busse R (2013) Comparison of hospital costs and lenght of stay associated with open-mesh, totally extraperitoneal inguinal hernia repair, and transabdominal preperitoneal inguinal hernia repair: an analysis of observational data using propensity score matching. Surg Endosc 27(4):1326-1333

18. Felix EL, Michas CA, Gonzales MH Jr (1995) Laparoscopic hernioplasty TAPP vs. TEP. Surg Endosc 9:984-989

19. Ramshaw BJ, Tucker JG, Conner T, Mason EM, Duncan TD, Lucas GW (1996) A comparison of the approaches to laparoscopic herniorraphy. Surg Endosc 10(1):29-32

20. Cohen RV, Alvarez G, Roll S, Garcia ME, Kawahara N, Schiavon CA, Schaffa TD, Pereira PR, Margarido NF, Rodrigues AJ (1998) Transabdominal or totally extraperitoneal laparoscopic hernia repair. Surg Laparosc Endosc 8(4):264-268

21. Czechowski A, Schafmayer A (2003) TAPP vs. TEP. Chirurg 74:1143-1148

22. Belyansky I, Tsirline VB, Klima DA, Walters AL, Lincourt AE, Heniford TB (2011) Prospective, comparative study of postoperative quality of life in TEP, TAPP, and modified Lichtenstein repairs. Ann Surg 254(5):709-714

23. Shah NR, Mikami DJ, Cook C, Manilchuk A, Hodges C, Memark VR, Volckmann ET, Hall CR, Steinberg S, Needleman B, Hazey JW, Melvin WS, Narula VK (2011) A comparison of outcomes between open and laparoscopic surgical repair of recurrent inguinal hernias. Surg Endosc 25:2330-2337

24. Zanghì A, Di Vita M, Lo Menzo E, Castorina S, Cavallaro AS, Piccolo G, Grosso G, Cappellani A (2011) Multicentric evaluation by Verbal Rate Scale and EuroQoL-5D of early and late post-operative pain after TAPP and TEP procedures with mechanical fixation for bilateral inguinal hernias. Ann Ital Chir 82(6):437-442

25. Stechemesser B, Jacob DA, Schug-Paß C, Köckerling F (2012) Herniamed: an internet-based registry for outcome research in hernia surgery. Hernia 16(3):269-276. doi:10.1007/s10029-0120908-3

26. Simons MP, Aufenacker T, Bay-Nielsen M, Bouillot JL, Campanelli G, Conze J, de Lange D, Fortelny R, Heikkinen T, Kingsnorth A, Kukleta J, Morales-Conde S, Nordin P, Schumpelick V, Smedberg S, Smietanski M, Weber G, Miserez M (2009) European Hernia Society guidelines on the treatment of inguinal hernia in adult patients. Hernia 13:343-403

27. Miserez M, Alexandre JH, Campanelli G, Corcione F, Cuccurullo D, Pascual MH, Hoeferlin A, Kongsnorth AN, Mandala V, Palot JP, Schumpelick V, Simmermacher RK, Stoppa R, Flament JB (2007) The European hernia society groin hernia classification: simple and easy to remember. Hernia 11:113-116

28. Köckerling F, Schug-Pass C (2014) Tailored approach in inguinal hernia repair-decision tree based on the guidelines. Front Surg 1:20. doi:10.3389/fsurg. 2014.00020 
29. Bittner R, Arregui ME, Bisgaard T, Dudai M, Ferzli GS, Fitzgibbons RJ, Fortelny RH, Klinge U, Kockerling F, Kuhry E, Kukleta J, Lomanto D, Misra MC, Montgomery A, MoralesConde S, Reinpold W, Rosenberg J, Sauerland S, Schug-Paß C, Singh K, Timoney M, Weyhe D, Chowbey P (2011) Guidelines for laparoscopic (TAPP) and endoscopic (TEP) treatment of inguinal Hernia [International Endohernia Society (IEHS)]. Surg Endosc 25:2773-2843
30. Bittner R, Montgomery MA, Arregui E, Bansal V, Bingener J, Bisgaard T, Buhck H, Dudai M, Ferzli GS, Fitzgibbons RJ, Fortelny RH, Grimes KL, Klinge U, Koeckerling F, Kumar S, Kukleta J, Lomanto D, Misra MC, Morales Conde S, Reinpold W, Rosenberg J, Singh K, Timoney M, Weyhe D, Chowbey P (2014) Update of guidelines on laparoscopic (TAPP) and andonscopic (TEP) treatment of inguinal hernia (International Endohernia Society). Surg Endosc. doi:10.1007/s00464-014-3917-8 